\title{
HOX-7 suppresses body weight gain and adipogenesis-related gene expression in high-fat-diet-induced obese mice
}

Heon-Myung Lee ${ }^{1}$, Hong-Kun Rim', Jong-Hwan Seo ${ }^{1}$, Yoon-Bum Kook ${ }^{2}$, Sung-Kew Kim ${ }^{3}$, Chang-Hyun Oh${ }^{3}$, Kyung Ho Yoo ${ }^{4}$, Jong-Sik Jin ${ }^{5}$ and Hyo-Jin $\mathrm{An}^{1 *}$

\begin{abstract}
Background: HOX-7 is a newly developed dietary formula composed of traditional oriental herbal medicines. The formula was developed with the aim of improving weight control. We investigated the anti-obesity effect of HOX-7 on high-fat-diet (HFD)-induced obesity in C57BL/6 mice.

Methods: The mice were divided into four groups and were fed a normal diet (ND), HFD, or HFD with oral administration of HOX-7 at 100 or $200 \mathrm{mg} / \mathrm{kg} /$ day for 12 weeks. Body and fat weight, histological changes of fat tissue, and the expression of key adipogenic transcription factors were investigated.

Results: The body weight of mice fed the HFD with HOX-7 was significantly decreased compared to the HFD group. There were no obvious differences in weekly food intake among the 4 groups. The weight of the epididymal and total fat pads was reduced in mice fed the HFD with HOX-7. Treatment with HOX-7 also substantially attenuated the expression of key adipogenic transcription factors, including peroxisome proliferatoractivated receptor $\gamma$, CCAAT/enhancer binding protein $a$, sterol regulatory element binding protein $1 c$, adipocyte $P 2$, liver $\mathrm{X}$ receptor, and lipoprotein lipase in the epididymal adipose tissue.
\end{abstract}

Conclusion: Overall, this study highlighted the anti-obesity effects of HOX-7, a finding that could contribute to the development of natural anti-obesity herbal medicines.

Keywords: C/EBPa, Mice, Obesity, PPARY, SREBP1C, Traditional herbal medicine

\section{Background}

Obesity is one of the most prevalent metabolic diseases in the world and constitutes a serious threat in both industrialized and developing countries [1]. It is connected with the genesis or development of various diseases, such as hypertension, cardiac arrhythmia, constipation, headache, steatorrhea, type 2 diabetes mellitus, and cancer $[2,3]$. The process of gaining fat involves increased adipogenesis accompanied by adipocyte differentiation. This differentiation is regulated by a highly organized cascade involving numerous transcription factors [4]. Among them, peroxisome proliferator-activated receptor $\gamma$ (PPAR $\gamma$ ), CCAAT/ enhancer binding protein $\alpha(\mathrm{C} / \mathrm{EBP} \alpha)$, and sterol regulatory

\footnotetext{
* Correspondence: hjan@sj.ac.kr

'Department of Pharmacology, College of Oriental Medicine, Sangji

University, Wonju-si, Gangwon-do 220-702, Republic of Korea

Full list of author information is available at the end of the article
}

element binding protein 1c (SREBP1c) are the major transcriptional genes involved in adipogenesis $[4,5]$.

To target obesity, current pharmacotherapy strategies are grouped into two categories [6]. The first category is to medicate people with obesity with drugs, including suppressants and anorexics, that can suppress food intake by regulating the central nervous system. The second category involves drugs that inhibit the absorption of specific nutrients in food [7]. However, these drugs, of which there are two varieties, can have undesirable side effects, such as hypertension, cardiac arrhythmia, constipation, and headache [8].

Because of the unavoidable side effects of the currently available anti-obesity drugs, the development of herbal medicinal products to treat obesity has become a global focus and there are many studies concerning natural medicines that might have beneficial effects in obese patients. 
Some natural compounds, plants and formulas, such as berberine, prunetin, aster glehni, and taeumjowi-tang have proven anti-obesity effects [9-12]. As well as these studies, there is a lot of research in progress globally to develop effective and safe natural anti-obesity drugs.

HOX-7 is a newly combined formula for treating obesity, composed of seven herbs (Coicis semen, Nelumbo nucifera, Saliconia herbacea, Polygoni Multiflori Radix, Raphani semen, Piperis Longi Fructus, and Atractylodis Rhizoma). Coicis semen is an adlay seed and was reported to have anti-obesity effects in humans [13]. Nelumbo nucifera has also been reported to show anti-obesity and hypolipidemic effects and decrese the expression of PPAR $\gamma$ [14]. Recent research on Saliconia herbacea revealed its antioxidant and anti-proliferative properties [15]. In addition, Saliconia herbacea has also been reported to have an adipogenesis inhibition effect [16]. Polygoni Multiflori Radix has been used in the treatment of obesity and hyperlipidemia in East Asian countries for centuries, and a recent study demonstrated its effects in obesity [17]. Raphani Semen, commonly known as radish seed, is used as a traditional medicine to treat constipation, chronic tracheitis, and hypertension [18]. Furthermore, Raphani Semen, which has a high linolenic acid content, could have effects that reduce the risk of cardiovascular disease and was revealed to have anti-oxidative activity [19]. Piperis Longi Fructus was verified for its anti-diabetic and anti-hyperlipidemic effects [20]. Atractylodis Rhizoma was discovered to have an anti-inflammatory effect [21] and anti-obesity effect in 3T3-L1 cells and animal model [22]. Based on these studies, we examined the anti-obesity effects of $\mathrm{HOX}-7$ in high-fat-diet (HFD)-induced obese mice.

\section{Methods}

\section{Reagents}

Coicis semen, Nelumbo nucifera, Saliconia herbacea, Polygoni Multiflori Radix, Raphani Semen, Piperis Longi Fructus, and Atractylodis Rhizoma were purchased from Omniherb Co. Ltd (Daegu, Republic of Korea). The normal diet (ND) and HFD were obtained from Research Diets (New Brunswick, NJ, USA). PPAR $\gamma, \mathrm{C} / \mathrm{EBP} \alpha$, SREBP1c, and $\beta$-actin monoclonal antibodies were purchased from Santa Cruz Biotechnology (Santa Cruz, CA, USA). The other reagents were purchased from Sigma-Aldrich (St. Louis, MO, USA).

\section{Preparation of HOX-7 extract}

HOX-7 is composed of Coicis semen (260 g), Nelumbo nucifera (416 g), Saliconia herbacea (91 g), Polygoni Multiflori Radix (130 g), Raphani Semen (143 g), Piperis Longi Fructus (52 g), and Atractylodis Rhizoma (208 g). The dried herbs were refluxed with $70 \%$ ethanol for $3 \mathrm{~h}$ at $80^{\circ} \mathrm{C}$. The extract was filtered and refluxed again under the same conditions. After filtration, the extract was completely dried using a freeze-dryer to obtain a solid ethanol extract. The yield was 17\% (17 g per $100 \mathrm{~g}$ of total materials)

\section{Animal experiments}

Male C57BL/6 J mice (3 - 4 weeks) were purchased from Daehan Biolink (DaeJeon, Republic of Korea). Mice were maintained (4 mice/cage) under a $12 \mathrm{~h}$ light/dark cycle, at $22 \pm 2^{\circ} \mathrm{C}$, and a relative humidity of $55 \pm 10 \%$, under conditions that followed the National Institutes of Health guidelines and were approved by the Ethical Committee for Animal Care and the Use of Laboratory Animals, Sangji University (reg. no. 2014-3). Mice were given the diet and water ad libitum. After 1 week of acclimation, 32 mice were divided randomly and equally into 4 groups ( $n=8$ per group); the ND group, HFD group, and HFD with HOX-7 at 100 or $200 \mathrm{mg} / \mathrm{kg}$ (H100 or H200 respectively). ND group were fed a commercial standard chow diet and HFD group were fed the HFD for 12 weeks. HOX-7 was dissolved in DW and, orally and daily administrated for 12 weeks with HFD. Food intake and body weight were recorded every week. At the end of the experimental period, the mice were fasted overnight. The next day, animals were anesthetized with zoletil (Virbac, Carros Cedex, France) and their visceral fat pads were excised, weighed immediately, and stored at $-80^{\circ} \mathrm{C}$.

\section{Histological analysis}

Representative epididymal adipose tissues from each group were fixed with $4 \%$ paraform aldehyde and embedded in paraffin. Sections of adipose tissue were cut and stained with hematoxylin and eosin (H\&E) for analysis of adipocyte surface area and diameter. The images of the stained slides were observed using a SZX10 microscope (Olympus, Seoul, Republic of Korea) and photographed. Digital images were taken from each slide (5 per group), and adipocyte diameters were measured using Image J software.

\section{Quantitative Real-time polymerase chain reaction (PCR) analysis}

Total RNA was isolated from the homogenized epididymal adipose tissues using TRIzol Reagent (Life Technologies, NY, USA), according to the manufacturer's instructions. The total RNA was then quantified using an Epoch microvolume spectrophotometer system (BioTek Instruments Inc, VT, USA). Synthesis of cDNA was carried out with quantified equal amounts of total RNA using a high-capacity cDNA reverse transcription kit (Applied Biosystems, CA, USA). The program was set for $60 \mathrm{~min}$ of initiation at $45^{\circ} \mathrm{C}$, followed by $5 \mathrm{~min}$ of incubation at $95^{\circ} \mathrm{C}$, and then maintained at $4^{\circ} \mathrm{C}$. A Step One Plus ${ }^{\circ}$ Real-time PCR system with an SYBR Green Master Mix (Applied Biosystems) and primers (Bioneer, Seoul, Republic of Korea) were used 
to perform a real-time PCR. All primer sequences are shown in Table 1 . The steps were as follows: $10 \mathrm{~min}$ at $95^{\circ} \mathrm{C}, 40$ cycles of $15 \mathrm{~s}$ at $95^{\circ} \mathrm{C}, 45 \mathrm{~s}$ at $58^{\circ} \mathrm{C}$, a final melting curve of $15 \mathrm{~s}$ at $95^{\circ} \mathrm{C}, 1 \mathrm{~min}$ at $60^{\circ} \mathrm{C}$, and $15 \mathrm{~s}$ at $95^{\circ} \mathrm{C}$. Fold changes of gene expression were calculated using the comparative threshold cycle $(\mathrm{Ct})$ method (Applied Biosystems). Each value was normalized for the initial control, glyceraldehydes-3-phosphate dehydrogenase (GAPDH).

\section{Western blot analysis}

The epididymal tissues dissected from the experimental animals were homogenized in a commercial lysis buffer PRO-PREP ${ }^{\oplus}$ (Intron Biotechnology Inc., Gyeongi-do, Republic of Korea) and centrifuged at $13000 \mathrm{rpm}\left(4^{\circ} \mathrm{C}\right)$ for $5 \mathrm{~min}$. Subsequently, the supernatant was transferred to a fresh $1.5 \mathrm{ml}$ tube. The quantification of the protein was carried out using Bio-Rad protein assay reagent. Each protein sample was loaded on Tris-glycine SDSpolyacrylamide gels, followed by transfer to polyvinylidene difluoride (PVDF) membranes (Millipore, MA, USA). The membranes were then blocked with $5 \%$ skim milk in Trisbuffered saline containing $0.1 \%$ Tween 20 (TBST) at room temperature for $1 \mathrm{~h}$ and incubated at $4{ }^{\circ} \mathrm{C}$ overnight with 1:1000 dilutions of the primary antibodies. The following day, the membranes were washed with TTBS 3 times for 10 min each and reacted with 1:2500 dilutions of the secondary antibodies for $2 \mathrm{~h}$ at room temperature. After reaction, immunoreactive protein bands were visualized using enhanced chemiluminescence (Santa Cruz Biotechnology). Bio-rad Quantity One ${ }^{\oplus}$ Software was used for the densitometric analysis.

\section{Statistical analysis}

All the values reported have been expressed as the mean \pm SE. Data were analyzed using one-way analysis of variance (ANOVA) with Dunnett's test. Statistical analysis was performed using GraphPad Prism (version 5) and $P<0.05$ was accepted as statistically significant.

\section{Table 1 Primer sequences}

\begin{tabular}{|c|c|c|}
\hline $\begin{array}{l}\text { Gene } \\
\text { name }\end{array}$ & $\begin{array}{l}\text { Forward primers } \\
\qquad\left(5^{\prime}-3^{\prime}\right)\end{array}$ & $\begin{array}{c}\text { Backward primers } \\
\left(5^{\prime}-3^{\prime}\right)\end{array}$ \\
\hline PPARY & TTCGGAATCAGCTCTGTGGA & CCATTGGGTCAGCTCTTGTG \\
\hline C/EBPa & AAACAACGCAACGTGGAGAC & ACCAAGGAGCTCTCAGGCAC \\
\hline SREBP1C & ATCGCAAACAAGCTGACCTG & AGATCCAGGTTTGAGGTGGC \\
\hline LXR & TCCTACACGAGGATCAAGCG & AGTCGCAATGCAAAGACCTC \\
\hline LPL & AGGACCCCTGAAGACACAGC & TTGGGCACCCAACTCTCATA \\
\hline aP2 & AGCATCATAACCCTAGATGG & GAAGTCACGCCTTTCATAAC \\
\hline
\end{tabular}

\section{Results}

Effects of HOX-7 on body weight and total fat mass in HFD-induced obese mice

Figure 1 indicates the changes in body weight and the visceral fat pads, both of which were obviously greater in the HFD group than in the ND group. However, the weights in the $\mathrm{H} 100$ and $\mathrm{H} 200$ groups were less than those in the HFD group (Figure 1A). Moreover, although there was no significant difference in food intake, the weight gain showed certain differences between the HFD group and HOX-7 groups (Figure $1 \mathrm{~B}$ and $\mathrm{C}$ ). Changes in the weight of the visceral fat pads, including the epididymal, retroperitoneal, and mesenteric fat pads, were in line with body weight changes (Figure 1D). The HFD group fats were more highly induced than any other group, whereas the HOX-7 groups showed evident suppression of fat production.

\section{Effect of HOX-7 on the accumulation of lipid droplets in epididymal adipose tissue}

To determine whether the observed decrease in body and visceral fat weight was due to reduced accumulation of fat, we stained representative adipose tissues with H\&E. As shown in Figure 2, enlargement of adipocytes in the visceral adipose tissue of mice in the HFD group was clearer than that the ND group. In addition, it was revealed that lipid accumulation in the visceral adipose tissue was definitely suppressed in the H100 and H200 groups compared with the HFD group (Figure 2A). Because fatty degeneration in adipose tissues is easy to identify, we compared the diameter of lipid droplets in the adipose tissues. As shown in Figure 2B, administration of HOX-7 significantly decreased the diameter of the lipid droplets.

\section{Effects of HOX-7 on the expression of adipocyte-specific mRNAs}

To determine the inhibitory effects of HOX-7 on adipogenic mRNA expression induced by the HFD in epididymal adipose tissue, we carried out a quantitative real-time PCR analysis. HOX-7 decreased the expression of mRNA with regard to adipogenesis. PPAR $\gamma$, the adipogenic key transcription factor, was significantly reduced in the adipose tissue taken from the HOX-7-treated HFD groups in a concentration dependent manner (Figure 3A). In addition, $\mathrm{C} / \mathrm{EBP} \alpha$ and SREBP1c showed similarly reduced expression (Figure 3B and C). Other adipogenic markers such as adipocyte P2 (aP2), lipoprotein lipase (LPL), and liver X receptor (LXR) were markedly reduced in the epididymal adipose tissue of HOX-7-treated mice (Figure 3D - F).

\section{Effects of HOX-7 on the expression of adipocyte-specific proteins}

To confirm the inhibitory effects of $\mathrm{HOX}-7$ on adipogenic mRNA expression, the expression of key adipogenic 

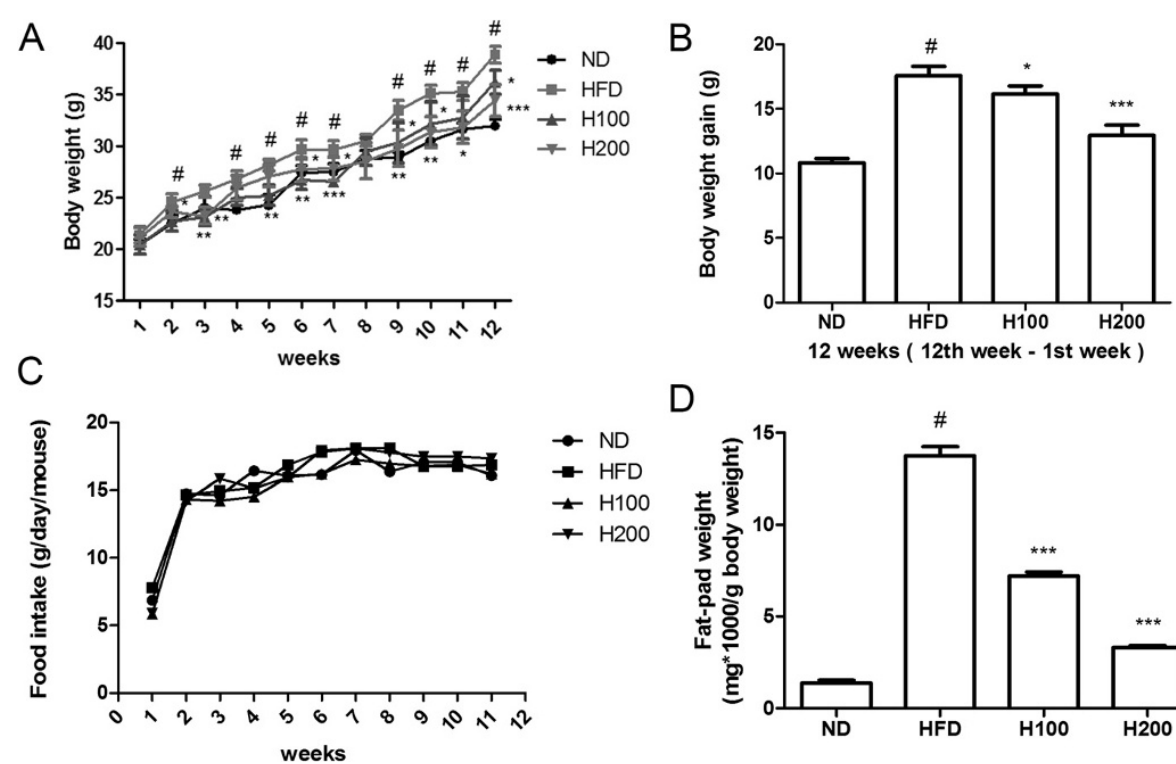

D

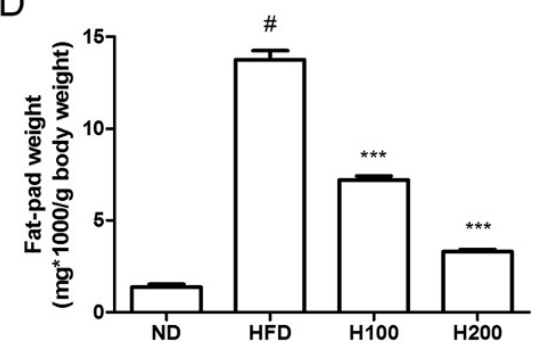

Figure 1 Effects of HOX-7 on body weight gain, fat-pads weights in HFD mice. Mice were fed ND or HFD for 12 weeks in the presence or absence of HOX-7. (A) Total body (g). (B) Body weight gain (g). (C) Food intake. (D) Visceral fat-pad weight. ND: Normal diet group; HFD: High fat diet group; H100: HOX-7 (100 mg/kg/day, po) treated with HFD group; H200: HOX-7 (200 mg/kg/day, po) treated with HFD group. The values are represented as mean \pm SE $(n=8) .{ }^{*} P<0.05$ versus ND group. ${ }^{*} P<0.05$, ${ }^{* *} P<0.01$, and ${ }^{* * *} P<0.001$ versus HFD group.

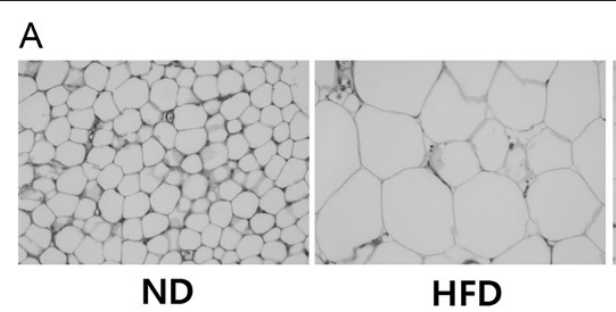

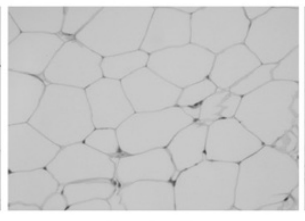

$\mathrm{H} 100$

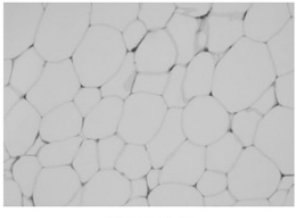

$\mathrm{H} 200$

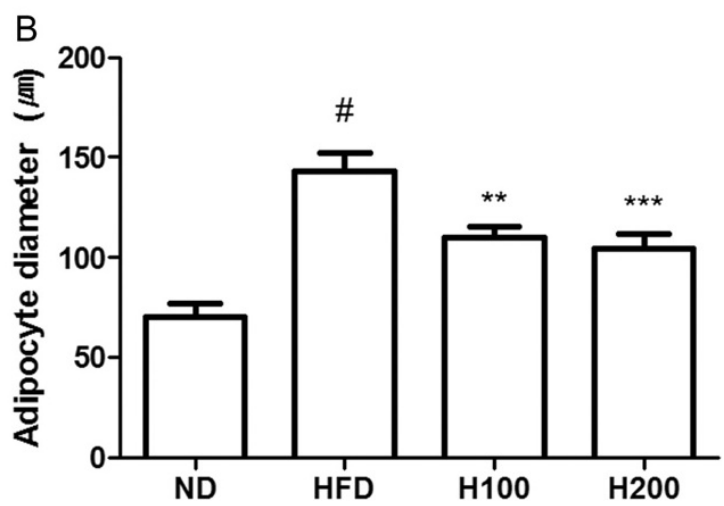

Figure 2 Effect of HOX-7 on accumulation of lipid droplets in epididymal adipose tissue. (A) Representative histological images of the epididymal adipose tissue were assessed by H\&E staining and examined using a light microscope; magnification: $\times 400$. (B) Adipocyte diameter. ND: Normal diet group; HFD: High fat diet group; H100: HOX-7 (100 mg/kg/day, po) treated with HFD group; H200: HOX-7 (200 mg/kg/day, po) treated with HFD group. ${ }^{\#} P<0.05$ versus ND group. ${ }^{* *} P<0.01$, and ${ }^{* *} P<0.001$ versus HFD group. 

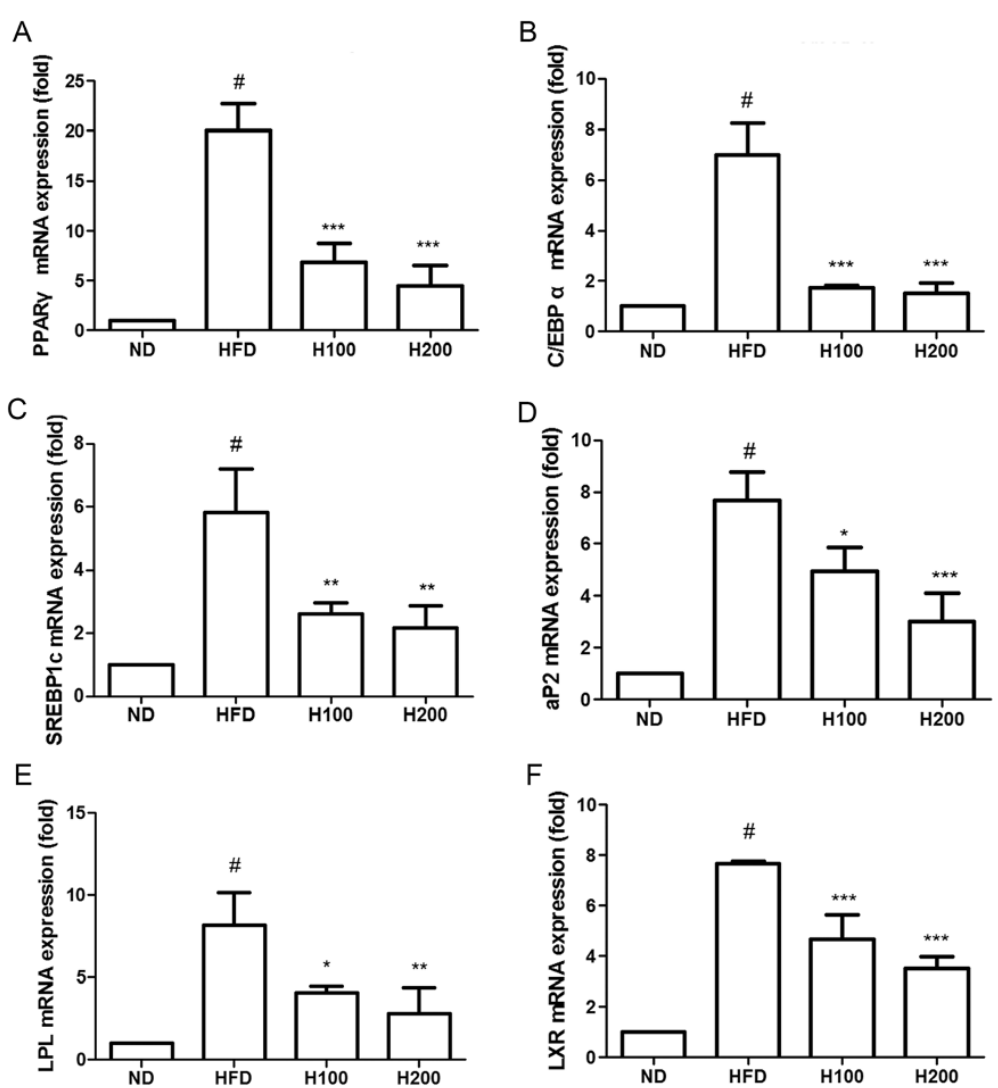

Figure 3 Effects of HOX-7 on mRNA expression of adipogenesis related genes in epididymal adipose tissue. mRNA expression of (A) PPARY, (B) C/EBPa, (C) SREBP1C, (D) aP2, (E) LPL, (F) LXR. Total RNA was prepared for the real-time-PCR analysis of adipogenesis-related genes expressions from adipose tissues. Real-time PCR analysis was conducted using a Step One Plus ${ }^{\circledR}$ Real-time PCR system. Data were normalized to the GAPDH mRNA levels. ND: Normal diet group; HFD: High fat diet group; H100: HOX-7 (100 mg/kg/day, po) treated with HFD group; H200: HOX-7 (200 mg/kg/day, po) treated with HFD group. The values are represented as mean \pm SE $(n=8)$ of three independent experiments. ${ }^{\#} P<0.05$ versus ND group. ${ }^{*} P<0.05,{ }^{* *} P<0.01$, and ${ }^{* * *} P<0.001$ versus HFD group.

proteins was investigated by Western blot analysis. In parallel with mRNA expression, the amounts of the PPAR $\gamma, \mathrm{C} / \mathrm{EBP} \alpha$, and SREBP1c proteins were reduced in epididymal adipose tissue obtained from HOX-7treated HFD mice than from mice given HFD alone (Figure 4).

\section{Discussion}

Globally, obesity is the most prevalent health problem affecting all age groups and numerous studies have focused on developing natural anti-obesity herbal medicines [23]. In line with these worldwide trends in anti-obesity research, we investigated the anti-obesity effect of $\mathrm{HOX}-7$
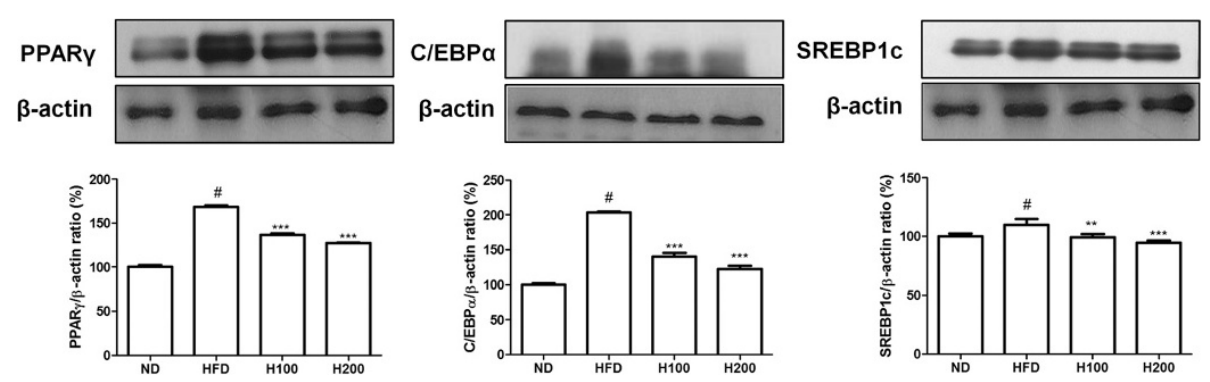

Figure 4 Effects of HOX-7 on expression of adipogenesis related proteins. Protein levels of PPARY, C/EBPa, and SREBP1C were determined by Western blotting. ND: Normal diet group; HFD: High fat diet group; H100: HOX-7 (100 mg/kg/day, po) treated with HFD group; H200: HOX-7 (200 mg/kg/day, po) treated with HFD group. The values are represented as mean \pm SE of three independent experiments. ${ }^{\sharp} P<0.05$ versus ND group. ${ }^{* *} P<0.01$, and ${ }^{* *} P<0.001$ versus HFD group. 
and showed that it significantly reduced body and visceral fat weight in HFD-induced obese mouse model. In addition, we found that HOX-7 suppressed adipogenesis in epididymal adipose tissues.

Obesity is the result of a complicated process regulated by a number of adipogenic transcription factors [24]. PPAR $\gamma$ is a ligand-activated transcriptional factor that has a key role in adipocyte differentiation [25]. It is mostly expressed in adipose tissues and required for differentiation of preadipocytes to mature adipocytes [25]. PPAR $\gamma$ activity is evoked when adipocyte differentiation starts, and it transfers hormonal stimulation to its target genes, one of which is C/EBP $\alpha$. When C/EBP $\alpha$ responds to a PPAR $\gamma$ stimulus, it cooperates with PPAR $\gamma$ to achieve adipocyte differentiation. Although the initial expression of C/EBPa is induced by the PPARy signal, it functions to further strengthen PPAR $\gamma$ activities by stimulating many specific genes required for adipocyte differentiation [26]. Additionally, SREBP1c is required for optimal adipocyte differentiation. It regulates the transcription of many genes related to lipid, fatty acid, and glucose metabolism [27]. Interestingly, SREBP1c participates in the production of an endogenous PPAR $\gamma$ ligand that reinforces PPAR $\gamma$ activity, which means that PPAR $\gamma$ might be a target gene of SREBP1c [28]. Thus, PPAR $\gamma, \mathrm{C} / \mathrm{EBP} \alpha$, and SREBP1c are believed to be crucial to, and perform a leading role in, the progression of adipocyte differentiation. In this study, we examined the effect of HOX-7 on the expression of various adipogenesis-related genes and found that HOX-7 inhibited the expression of PPAR $\gamma, \mathrm{C} / \mathrm{EBP} \alpha$, and SREBP1c in epididymal adipose tissues. These results suggest that HOX-7 exerts anti-obesity effects through the regulation of adipogenic transcription factors.

The transcription factors $\mathrm{aP} 2$ and LPL are downstream targets of PPAR $\gamma$ and C/EBP $\alpha$ [29]. Therefore, the gene expression of aP2 and LPL indicates the transcriptional activities of PPAR $\gamma$ and C/EBP $\alpha$. We found that HOX-7 suppressed the gene expression of aP2 and LPL, thus further confirming the inhibitory effect of $\mathrm{HOX}-7$ on the expression of PPAR $\gamma$ and C/EBP $\alpha$. LXR is primarily considered a regulator of cholesterol and fatty acid metabolism in liver tissue and macrophages [30]. LXR similarly stimulates adipocyte differentiation through the induction of PPARy expression [31]. LXR forms a positive relationship with PPARY and mediates adipogenesis by affecting adipogenic transcriptional factors. In this study, HOX-7 also attenuated the expression of LXR at the mRNA level.

\section{Conclusions}

In summary, HOX-7 significantly suppressed body and visceral fat weight in an HFD-induced obese mouse model. HOX-7 inhibited the expression of adipogenesisrelated genes, such as PPAR $\gamma, \mathrm{C} / \mathrm{EBP} \alpha$, and SREBP1c.
Our findings suggest that HOX-7 could represent a novel natural anti-obesity herbal medicine.

\section{Competing interests}

The authors declare that they have no competing interests.

\section{Authors' contributions}

All experimental work was done by $\mathrm{HL}$, JS, and JJ. HL, HR, YK, and HA wrote the draft of manuscript, tabulated the data, and collected some references. SK, CO, KY made and supplied HOX-7 and other reagents. All authors participated in the design of the study data, read and approved the final manuscript.

\section{Acknowledgements}

This work was supported by Seoul R\&BD program (Grant number, Rl120003), and Sangji University Research Fund, 2013. We would like to thank Korea institute of science and technology (KIST) and CTCBIO Inc., Republic of Korea, for kind contribution to the chemical and medicinal experiments.

\section{Author details}

${ }^{1}$ Department of Pharmacology, College of Oriental Medicine, Sangji University, Wonju-si, Gangwon-do 220-702, Republic of Korea. ${ }^{2}$ Department of Presctiption, College of Oriental Medicine, Sangji University, Wonju-si, Gangwon-do 220-702, Republic of Korea. ${ }^{3}$ Center for Biomaterials, Korea Institute of Science and Technology (KIST), PO Box 131, Cheongryang, Seoul 130-650, Republic of Korea. ${ }^{4}$ Chemical Kinomics Research Center, Korea Institute of Science and Technology (KIST), PO Box 131, Cheongryang, Seoul 130-650, Republic of Korea. ${ }^{5}$ Department of Oriental Medicine Resources, College of Environmental \& Bioresources Sciences, Chonbuk National University, Jeonju, Jeonbuk, Republic of Korea.

Received: 23 September 2014 Accepted: 9 December 2014

Published: 17 December 2014

\section{References}

1. He GW, Qu WJ, Fan B, Jing R, He R: The protective effect of Yi-Qi-Yang-Yin-Ye, a compound of traditional Chinese herbal medicine in diet-induced obese rats. Am J Chin Med 2008, 36:705-717.

2. Kopelman PG: Obesity as a medical problem. Nature 2000, 404:635-643.

3. Pischon T, Nothlings U, Boeing H: Obesity and cancer. Proc Nutr Soc 2008, 67:128-145.

4. Lefterova MI, Lazar MA: New developments in adipogenesis. Trends Endocrinol Metab 2009, 20:107-114.

5. Rosen ED, Walkey CJ, Puigserver P, Spiegelman BM: Transcriptional regulation of adipogenesis. Genes Dev 2000, 14:1293-1307.

6. Korner J, Aronne LJ: Pharmacological approaches to weight reduction: therapeutic targets. J Clin Endocrinol Metab 2004, 89:2616-2621.

7. Seo JB, Choe SS, Jeong HW, Park SW, Shin HJ, Choi SM, Park JY, Choi EW, Kim JB, Seen DS, Jeong JY, Lee TG: Anti-obesity effects of Lysimachia foenum-graecum characterized by decreased adipogenesis and regulated lipid metabolism. Exp Mol Med 2011, 43:205-215.

8. Luque CA, Rey JA: Sibutramine: a serotonin-norepinephrine reuptake-inhibitor for the treatment of obesity. Ann Pharmacother 1999, 33:968-978.

9. Yoo JH, Lee EJ, Kwak CK, Sohn EH, Koh BH, Song IB, Lee KS: Clinical trial of herbal formula on weight loss in obese Korean children. Am J Chin Med 2005, 33:713-722.

10. Lee YS, Kim WS, Kim KH, Yoon MJ, Cho HJ, Shen Y, Ye JM, Lee CH, Oh WK, Kim CT, Hohnen-Behrens C, Gosby A, Kraegen EW, James DE, Kim JB: Berberine, a natural plant product, activates AMP-activated protein kinase with beneficial metabolic effects in diabetic and insulin-resistant states. Diabetes 2006, 55:2256-2264.

11. Ahn TG, Yang G, Lee HM, Kim MD, Choi HY, Park KS, Lee SD, Kook YB, $\mathrm{An} \mathrm{HJ}$ : Molecular mechanisms underlying the anti-obesity potential of prunetin, an O-methylated isoflavone. Biochem Pharmacol 2013, 85:1525-1533

12. Lee HM, Yang G, Ahn TG, Kim MD, Nugroho A, Park HJ, Lee KT, Park W, An HJ: Antiadipogenic Effects of Aster glehni Extract: In Vivo and In Vitro Effects. Evid Based Complement Alternat Med 2013, 2013:859624.

13. Kim SO, Yun SJ, Lee EH: The water extract of adlay seed (Coix lachrymajobi var. mayuen) exhibits anti-obesity effects through neuroendocrine modulation. Am J Chin Med 2007, 35:297-308. 
14. You JS, Lee YJ, Kim KS, Kim SH, Chang KJ: Anti-obesity and hypolipidaemic effects of Nelumbo nucifera seed ethanol extract in human pre-adipocytes and rats fed a high-fat diet. J Sci Food Agric 2014, 94:568-575.

15. Wang X, Zhang M, Zhao Y, Wang H, Liu T, Xin Z: Pentadecyl ferulate, a potent antioxidant and antiproliferative agent from the halophyte Salicornia herbacea. Food Chem 2013, 141:2066-2074.

16. Karadeniz F, Kim JA, Ahn BN, Kwon MS, Kong CS: Effect of Salicornia herbacea on Osteoblastogenesis and Adipogenesis in Vitro. Mar Drugs 2014, 12:5132-5147.

17. Li N, Chen Z, Mao X, Yu J, Zhao R: Effects of lipid regulation using raw and processed radix polygoni multiflori in rats fed a high-fat diet. Evid Based Complement Alternat Med 2012, 2012:329171.

18. Gutierrez RM, Perez RL: Raphanus sativus (Radish): their chemistry and biology. ScientificWorldJournal 2004, 4:811-837.

19. Sham TT, Yuen AC, Ng YF, Chan CO, Mok DK, Chan SW: A review of the phytochemistry and pharmacological activities of raphani semen. Evid Based Complement Alternat Med 2013, 2013:636194.

20. Kumar S, Sharma S, Vasudeva N: Screening of antidiabetic and antihyperlipidemic potential of oil from Piper longum and piperine with their possible mechanism. Expert Opin Pharmacother 2013, 14:1723-1736.

21. Resch M, Steigel A, Chen ZL, Bauer R: 5-Lipoxygenase and cyclooxygenase-1 inhibitory active compounds from Atractylodes lancea. J Nat Prod 1998, 61:347-350.

22. Kim CK, Kim M, Oh SD, Lee SM, Sun B, Choi GS, Kim SK, Bae H, Kang C, Min BI: Effects of Atractylodes macrocephala Koidzumi rhizome on 3T3-L1 adipogenesis and an animal model of obesity. J Ethnopharmacol 2011, 137:396-402

23. Hasani-Ranjbar S, Jouyandeh Z, Abdollahi M: A systematic review of anti-obesity medicinal plants - an update. J Diabetes Metab Disord 2013, 12:28.

24. Ristow M, Muller-Wieland D, Pfeiffer A, Krone W, Kahn CR: Obesity associated with a mutation in a genetic regulator of adipocyte differentiation. $N$ Engl J Med 1998, 339:953-959.

25. Kahn BB, McGraw TE: Rosiglitazone, PPARgamma, and type 2 diabetes. N Engl J Med 2010, 363:2667-2669.

26. Rosen ED, Hsu CH, Wang X, Sakai S, Freeman MW, Gonzalez FJ, Spiegelman BM: C/EBPalpha induces adipogenesis through PPARgamma: a unified pathway. Genes Dev 2002, 16:22-26.

27. Farmer SR: Transcriptional control of adipocyte formation. Cell Metab 2006, 4:263-273

28. Fajas L, Schoonjans K, Gelman L, Kim JB, Najib J, Martin G, Fruchart JC Briggs M, Spiegelman BM, Auwerx J: Regulation of peroxisome proliferator-activated receptor gamma expression by adipocyte differentiation and determination factor $1 /$ sterol regulatory element binding protein 1: implications for adipocyte differentiation and metabolism. Mol Cell Biol 1999, 19:5495-5503.

29. Tontonoz P, Hu E, Graves RA, Budavari Al, Spiegelman BM: mPPAR gamma 2: tissue-specific regulator of an adipocyte enhancer. Genes Dev 1994, 8:1224-1234.

30. Zhang X, Liu J, Su W, Wu J, Wang C, Kong X, Gustafsson JÅ, Ding J, Ma X, Guan Y: LXR activation increases hepatic fatty acid desaturation by the induction of SCD1 expression through an LXRalpha-SREBP1c-dependent mechanism. J Diabetes 2014, 6:212-220.

31. Seo JB, Moon HM, Kim WS, Lee YS, Jeong HW, Yoo E, Ham J, Kang H, Park MG, Steffensen KR, Stulnig TM, Gustafsson JA, Park SD, Kim JB: Activated liver $\mathrm{X}$ receptors stimulate adipocyte differentiation through induction of peroxisome proliferator-activated receptor gamma expression. Mol Cell Biol 2004, 24:3430-3444.

doi:10.1186/1472-6882-14-505

Cite this article as: Lee et al: HOX-7 suppresses body weight gain and adipogenesis-related gene expression in high-fat-diet-induced obese mice. BMC Complementary and Alternative Medicine 2014 14:505.

\section{Submit your next manuscript to BioMed Central and take full advantage of:}

- Convenient online submission

- Thorough peer review

- No space constraints or color figure charges

- Immediate publication on acceptance

- Inclusion in PubMed, CAS, Scopus and Google Scholar

- Research which is freely available for redistribution 